\title{
INTRODUCTION: \\ LANGUAGE USE IN AND ABOUT THE NET DRAMA SERIES SKAM
}

By guest editors

Elisabeth Muth Andersen

University of Southern Denmark

Søren Vigild Poulsen

University of Southern Denmark

Marianne Rathje

The Danish Language Council

The Norwegian youth series SKAM took most of the world by storm. The series was produced by the Norwegian public service channel NRK and was broadcast for four seasons on Norwegian TV from September 2015 to June 2017. During the same period, it was possible to stream the series on the Internet.

On January 30 2018, the University of Southern Denmark in Odense, Denmark, hosted a symposium entitled "Sproget i og omkring SKAM" ("The language in and around SKAM"). Since the series was first launched in Denmark in 2016, there have been a few research-related events in Denmark about SKAM. Examples of these include: "SKAM - en norsk public servicesucces" ("SKAM - a Norwegian public service success") at the University of Copenhagen and "SKAM set med mediebriller" ("SKAM seen through the eyes of the media") organized by the Danish-Norwegian cooperation fund both events having a media focus. At the symposium "The language in and around SKAM", language use in and around SKAM was addressed for the first time.

At the symposium, seven papers were given by the following researchers and with these (translated) titles: 
Pia Quist and Astrid Ravn Skovse (University of Copenhagen):

Language inside and outside SKAM: authenticity element, community marker and commodity

Søren Vigild Poulsen and Elisabeth Muth Andersen (University of Southern Denmark):

"Kødder du?" A multimodal perspective on digital mediated language use in SKAM

Line Nybro Petersen (University of Southern Denmark):

Language games and play atmosphere for the fans of SKAM

Ruth Vatvedt Fjeld (University of Oslo):

Words for feelings in SKAM - a Nordic perspective

Marianne Rathje (University of Southern Denmark):

Serr, SKAM-Norwegian in Danish?

Karoline Lassen (University of Aarhus):

Interskamdinavian: SKAM's influence on Danish language users'

understanding of Norwegian

Tina Thode Hougaard (University of Aarhus):

Shame in emojis - emojis in SKAM

After the symposium, we issued a call on behalf of the journal Scandinavian Studies in Language, and two articles were published as a result, namely Jennifer Duggan and Anne Dahl's article Fan translations of SKAM: Challenging Anglo linguistic and popular cultural hegemony in a transnational fandom and Elisabeth Muth Andersen and Søren Vigild Poulsen's contribution Viewing, listening and reading along: Linguistic and multimodal constructions of viewer participation in the net series SKAM.

The first article by Jennifer Duggan and Anne Dahl investigates how SKAM fans contribute to diffusing access to the SKAM universe by inviting, providing and discussing translations of scenes in SKAM in the comments section of the official SKAM website. Non-Norwegian speakers needed translations, because subtitles in English were not provided by NRK, since copyright restrictions prevented NRK from distributing the series outside Scandinavia.

As the authors argue, Anglo-American culture dominates mass popular culture, as much film and TV is produced in English and appears to take place in Anglo-American cultures. Therefore, the interest in SKAM outside Scandinavia, despite the lack of official subtitles, provides an interesting subject for the investigation of both online transnational fan culture and linguistic ideologies negotiated between local and transnational fans. 
Based on 1200 entries posted for season 3 of the series, the authors identity four recurrent themes related to fan translation that reveal users' approaches to fandom and their understandings of language ideologies.

Building on research on media fandoms (e.g. Hills 2002; Jenkins, Ford \& Green 2013), Duggan \& Dahl show that the SKAM fans have a collaborative approach to translation, use the demand for translation to create social ties, and use translations as ways to invoke the culture of gift-giving common to online media fandom.

Duggan \& Dahl also show how fans view relationships between languages and identities when they invite and provide translations. Whereas other studies on fan translation have tended to investigate translation as such, Duggan \& Dahl focus on fans' meta-discussions of translation from Norwegian primarily into English.

When dealing with the demand for English translations of a Norwegian cultural artefact, i.e. the SKAM series, Duggan \& Dahl find that fans' practices and discussions reveal a tension between linguistic and cultural protectionism on the one hand and a sense of pride in the show and a desire to share it with the world on the other hand. This tension relates to the fact that the language of translation is overwhelmingly English. Duggan \& Dahl found that some users view English as a threat to Norwegian (Graedler 2014), but the vast majority of commentators responded positively to requests for English translations. However, a native speaker ideal is not prevalent in the data; whereas knowledge of Norwegian is valued, knowledge of complex linguistic repertoires and in multiple languages (Cook 1992) is a required and highly valued subcultural capital that makes fan translations possible in this context. Hence, as argued by Duggan \& Dahl, based on a desire to understand and provide others with access to the language used in SKAM, online translation practices contribute to creating a community identity which is dependent on multicompetent fans, i.e. fans who are competent in several languages and willing to participate in the distribution of translations to an international audience.

Duggan \& Dahl's study, therefore, contributes with insights about how transnational fan cultures that are dependent on competencies in several languages may develop and how linguistic ideologies may be negotiated between them.

The second paper by Elisabeth Muth Andersen and Søren Vigild Poulsen explores how viewers are positioned in relation to interactions between fictional characters in SKAM.

Previous language and media studies have, among other things, pointed to degrees of mediation, viewers' sense of co-presence and their experience of authenticity in the fictional world of SKAM as characteristic dramaturgical effects. This study aims to elaborate on this research by showing how the 
features of mediation and sensed co-presence are accomplished by integrating cinematic resources and discursive strategies that the web series provides to its viewers.

The paper combines social semiotic multimodality theory (Kress \& van Leeuwen, 1996, 2001; Kress, 2010) for the analysis of the interaction of resources for communication with Goffman's (1981) work on participation frameworks, i.e. the various ways of participating in co-present and/or mediated communication. Furthermore, the study uses Dynel's (2011) twolevel model of communication in TV discourse. The first level concerns communication between the fictional characters and the second level includes the use of cinematic and discursive strategies by members of the film crew including, for example, scriptwriting, editing and shooting.

Focusing on a specific scene in the first season as a case example, the analysis shows how the viewer is represented as though physically present in the interactional space of the depicted fictional characters using cinematic resources such as camera placement, distance, height and focus, and how the viewer is invited to interpret the characters' employment of specific semiotic resources to organize and monitor their interactions in the shared space of the schoolyard of a high school in which the scene occurs, using shifts in shots, close-ups etc.

Thereby a so-called fictitious participation slot (Brock 2015:32) is constructed for the viewer. The study also shows how the access provided to characters' fictional interactions mediated by their mobile phones by indicating text bubbles on the viewers' screen supports these viewers' positioning in a particular scene. Thus, the paper seeks to ground previous findings in an empirical study of the complex multimodal ensemble of filmic resources in SKAM.

Based on these findings, Andersen and Poulsen argue that SKAM is remarkable in the way the web series exploits and integrates filmic resources, especially related to speech, writing and embodiment, enabling different viewer positions with distinct access to interactions between characters and information about the individuals. By employing multiple resources of communication in and across the communicative framework of the fictional characters and the communicative framework between the TV production and the viewers as recipients, these positionings work to create a sense of presence and identification for the viewer. In addition, by paying attention to the communicative functions of written (digital) language, spoken language and embodied resources, respectively, the study documents the complex construction of viewer positions in TV discourse. In addition, the analysis highlights how representations of digitally mediated communication (writing) on the viewer's screen expose how the digitally mediated communication space of one of the characters is integrated with the digitally mediated viewing space of the viewer. 
By combining multimodal analysis and participant frameworks, this study shows how SKAM provides different viewer positions and how the web series orchestrates these, thereby complementing existing linguistic and media studies.

\section{References}

Brock, A. (2015). "Participation frameworks and participation in televised sitcom, candid camera and stand-up comedy", in M. Dynel \& J. Chovanec (Eds.), Participation in public and social media interactions, John Benjamins, Amsterdam/ Philadelphia, pp. 27-47.

Cook, V. (1992). "Evidence for multicompetence”, Language Learning, Vol. 42 No. 4, pp. 557-591. doi:10.1111/j.1467-1770.1992.tb01044.x

Dynel, M. (2011). “"You talking to me?" The viewer as a ratified listener to film discourse", Journal of Pragmatics, Vol. 43 No. 6, pp. 1628-1644.

Goffman, E. (1981). Forms of talk, University of Pennsylvania Press, Philadelphia.

Graedler, A.-L. (2014). "Attitudes towards English in Norway: A corpus-based study of attitudinal expressions in newspaper discourse", Multilingua, 33, pp. 291-312. doi: 10.1515/multi-2014-0014.

Hills, M. (2002). Fan cultures, Routledge, London, England.

Jenkins, Ford, H. S. \& Green, J. (2013). Spreadable media, New York University Press, New York, NY.

Kress, G. (2010). Multimodality: A social semiotic approach to contemporary communication. Routledge, London.

Kress, G. and van Leeuwen, T. (1996). Reading images: The grammar of visual design. $1^{\text {st }}$ edition. Routledge, London.

Kress, G. \& Van Leeuwen, T. (2001). Multimodal discourse: The modes and media of contemporary communication. London: Arnold Publishers. 